\title{
AIRTRAQ® VERSUS MACINTOSH LARYNGOSCOPE FOR AIRWAY MANAGEMENT DURING GENERAL ANESTHESIA: A SYSTEMATIC REVIEW AND META-ANALYSIS OF RANDOMIZED CONTROLLED TRIALS
}

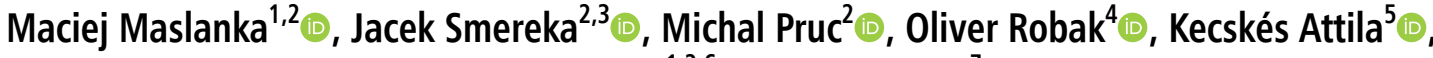 \\ Lukasz Szarpak ${ }^{1,2,6}{ }^{\infty}$, Kurt Ruetzler ${ }^{7}$ (D) \\ ${ }^{1}$ Maria Skłodowska-Curie Medical Academy in Warsaw, Poland \\ ${ }^{2}$ Polish Society of Disaster Medicine, Warsaw, Poland \\ ${ }^{3}$ Department of Emergency Medical Service, Wroclaw Medical University, Warsaw, Poland \\ ${ }^{4}$ Department of Medicine I, Medical University of Vienna, Austria \\ ${ }^{5}$ NATO Centre of Excellence for Military Medicine, Budapest, Hungary \\ ${ }^{6}$ Bialystok Oncology Center, Bialystok, Poland \\ ${ }^{7}$ Departments of Outcomes Research and General Anesthesiology, Anesthesiology Institute, Cleveland Clinic, Cleveland, Ohio, USA
}

\begin{abstract}
INTRODUCTION: Despite the introduction of supraglottic devices for ventilation, endotracheal intubation is still a gold standard for airway management in both prehospital and operating theatre conditions. This systematic review and meta-analysis were conducted to investigate the effectiveness and safety of Airtraq vs. Macintosh laryngoscope for endotracheal intubation during general anesthesia.

MATERIAL AND METHODS: The current issue of Pubmed, Embase, Cochrane, Web of science, Scopus (from database inception to October 20, 2020) was searched. Randomized controlled trials (RCT) comparing Airtraq and Macintosh laryngoscope were included in this meta-analysis. The primary outcomes were the success rate of first attempt intubation and intubation time. Secondary outcomes were overall intubation success rate, malposition, and adverse events. Review Manager 5.4 software was used to perform the pooled analysis and assess the risk of bias for each eligible RCT.
\end{abstract}

RESULTS: Seventeen studies were included in the review for data extraction. First attempt success rate was $85.6 \%$ for ATQ vs. $68.4 \%$ for MAC (OR $\left.=3.00 ; 95 \% \mathrm{Cl}: 1.37,6.60 ; p=0.006 ; I^{2}=63 \%\right)$. The use of ATQ and MAC for intubation in cervical spine immobilization was associated with the effectiveness of the first intubation attempt at $98.6 \%$ vs. $71.1 \%\left(\mathrm{OR}=16.40 ; 95 \% \mathrm{Cl}: 3.55,78.87 ; \mathrm{p}<0.001 ; \mathrm{I}^{2}=0 \%\right)$. Intubation time with ATQ was shorter than with MAC (MD = -3.19; $\left.95 \% \mathrm{Cl}:-9.33,2.95 ; p=0.31 ; I^{2}=97 \%\right)$. The endotracheal intubation during cervical spinal intubation was associated with significantly shorter procedure duration for ATQ than for MAC (MD = -10.30; 95\% Cl: $-18.43,-2.18 ; p=0.01 ; I^{2}=74 \%$ ). The total efficacy of intubation, which for ATQ and MAC varied and was $86.7 \%$ vs. $80.6 \%$ respectively $(\mathrm{OR}=2.88$; $95 \% \mathrm{Cl}: 1.61,5.13 ; \mathrm{p}<0.001 ; \mathrm{I}^{2}=0 \%$ ).

CONCLUSIONS: Based on the results of this analysis, we conclude that ATQ can reduce the failed first intubation attempt, especially in cervical manual inline stabilization patients, and reduces the time needed to obtain airway management, but does not provide significant benefits on other adverse events associated 
with tracheal intubation. Further studies are needed to demonstrate whether severe adverse events are significantly different between the two devices.

KEY WORDS: airway management, endotracheal intubation, laryngoscope, systematic review, meta-analysis

Disaster Emerg Med J 2021; 6(1): 1-9

\section{INTRODUCTION}

Various surgical procedures are performed under local and regional anesthesia. Much of the surgical procedures can be performed using supraglottic devices, but still, in many surgical procedures, general anesthesia is performed with airway protection by endotracheal intubation [1].

Providing adequate patient ventilation, airway management and especially endotracheal intubation are the basic procedures performed by an anesthesiologist [2]. Unfortunately, in some cases, endotracheal intubation is more or less difficult and in some cases may not be possible $[3,4]$. There are several scales for assessing the patient's airway and possible difficulties in endotracheal intubation. These scales facilitate the selection of the right technique, the preparation of appropriate equipment, including alternative ones, and above all, is based on the involvement of experienced medical personnel.

Improper airway management may result in a variety of complications, including the risk of death. This is particularly important in emergency and life-saving patients and airway procedures in emergency medicine. Unrecognized esophageal intubation may have catastrophic consequences for the patient [3]. The problem of difficult airways is particularly important in patients with the severe clinical course of COVID-19, where hypoxia progresses very quickly and difficulties in securing the airway may pose a real threat to the patient's life, especially in case of limitations for medical personnel related to the use of personal protective equipment and lack of instant assistance from more experienced medical personnel [5].

Various parameters can be used to assess the efficacy of airway management especially endotracheal intubation, including the total duration of the procedure, the percentage of successful intubations at the first attempt, the total number of intubation attempts, and the complications of endotracheal intubation for both normal and difficult airways, including cervical spine immobilization.

This systematic review and meta-analysis was conducted to investigate the effectiveness and safety of Airtraq vs. Macintosh laryngoscope for endotracheal intubation during general anesthesia.

\section{MATERIAL AND METHODS}

This systematic review and meta-analysis was conducted following the recommendations of The Cochrane Handbook for Systematic Reviews of Interventions and reported according to the Preferred Reporting Items for Systematic Reviews and Meta-analyses (PRISMA) statement [6]. Before starting the study, all authors agreed on the analysis methods and the inclusion and exclusion criteria to be applied.

\section{Data sources and search strategy}

Two authors (M.M. and L.S.) independently searched relevant literature. The current issue of Pubmed, Embase, Cochrane, Web of science, Scopus (from database inception to October 20, 2020) was searched. Study authors were mailed for any useful information. The whole search strategy used free words including 'Airtraq' OR 'ATQ' OR 'channeled laryngoscop*' AND 'Macintosh' OR 'MAC' OR 'direct laryngoscop*' AND 'endotracheal intubation' $O R$ 'tracheal intubation' OR 'intubation' OR 'airway' OR 'airway management' OR 'ETI'. The reference lists of all eligible trials and reviews were screened for additional citations. We restricted publication to the English language.

\section{Eligibility criteria}

Randomized controlled trials comparing Airtraq and Macintosh laryngoscope and reporting the efficacy parameters of tracheal intubations were included. The pre-hospital study, conference papers, letters to the editor, cadaver study, simulated study, or case reports were excluded.

\section{Data extraction}

Two reviewers (M.M. and J.S.) independently extracted data from each study by using a predefined data extraction form. Any disagreement unresolved by the discussion was resolved in consultation with 
a third reviewer (L.S.). The following variables were extracted from the studies: first author name, country, study design, airway management setting, type of operator, no. of patients, age, sex, the success of intubation attempts, intubation time, adverse events, inclusion and exclusion criteria, outcomes and findings. In case if the above variables were not found in the articles, we requested the data from their authors via email.

\section{Risk of bias assessment}

The risk of bias for each eligible study was independently assessed by two review authors (J.S. and M.M.). For randomized controlled trials, the Cochrane Collaboration's tool (The Cochrane Collaboration, Oxford, UK) was used to assess the risk of bias [7]. This tool is widely used to assess the methodological quality of RCTs and consists of the following six items: random sequence generation, allocation concealment, blinding of participants and personnel, blinding of outcome assessment, incomplete outcome data, and selective outcome reporting. According to the previous trials [8] each bias was graded 'yes', 'no', or 'unclear', which reflected a high risk of bias, low risk of bias, and uncertain bias, respectively.

\section{Statistical analysis}

Meta-analysis was performed by RevMan 5.4EN (Cochrane Collaboration, Oxford, UK). A two-tailed $p<0.05$ was considered statistically significant. All statistical variables were determined with $95 \%$ confidence interval $(\mathrm{Cl})$ to estimate the range of plausible treatment effects. In case when the continuous outcome was reported in a study as median, range, and interquartile range, we estimated means and standard deviations using the formula described by Hozo et al. [9]. We employed the inverse-variance method for the continuous outcomes and the Mantel-Haenszel models for all dichotomous outcomes. We calculated mean differences (MD) for continuous measurements and odds ratios (OR) for dichotomous outcomes.

Statistical heterogeneity across trials was estimated using the $\mathrm{I}^{2}$ statistic [10], in which $\mathrm{I}^{2}<30 \%$ denotes 'low heterogeneity', $I^{2}=30 \%$ to $50 \%$ represents 'moderate heterogeneity', and $I^{2}>50 \%$ denotes 'substantial heterogeneity' [11]. The random-effects model was used for $\mathrm{I}^{2}>50 \%$; otherwise, the fixed effects model was employed. The Mantel-Haenszel method was used to synthesize dichotomous data.

\section{RESULTS \\ Characteristics of included studies}

The search strategy details are provided in Figure 1. Using a search strategy, a total of 507 papers were identified. A total of 136 studies were removed due to duplicates. In the remaining 371 studies, 329 were excluded because of patients not eligible for the study purpose, abstract unavailable, reviews, or letters.

Twenty-five articles were excluded as follows: four were not RCT designed studies, four were only published abstracts, three were letters to the editor, seven evaluated different outcomes to this study (for the transitivity assumption not to be violated), six were simulation trials, and one was a redundant publication. Finally, 17 studies were eventually included in the review for data extraction [12-28].

\section{Risk of bias assessment for included studies}

Detailed description regarding the risk of bias of the included studies is shown in Supplementary digital content (SDC) of the 17 included studies, all were RCTs [12-28], and six of them were single-blinded $[12,13,22-25]$. All studies (100\%) were assessed as having a low risk of bias about selective reporting and other potential sources of bias.

\section{Primary outcome}

Twelve studies ( $n=782$ patients) reported the first attempt success rate of intubation with ATQ and MAC $[12,13,17,18,20-26,28]$. In case of ATQ first attempt success rate was $85.6 \%$ vs. $68.4 \%$ for MAC $(O R=3.00 ; 95 \% \mathrm{Cl}: 1.37,6.60 ; \mathrm{p}=0.006$; $1^{2}=63 \%$; Figure 2). The additional analysis showed that the use of ATQ and MAC in cervical spine immobilization was associated with the effectiveness of the first intubation attempt at $98.6 \%$ vs. $71.1 \%$ $(\mathrm{OR}=16.40 ; 95 \% \mathrm{Cl}: 3.55,78.87 ; \mathrm{p}<0.001$; $\mathrm{I}^{2}=0 \%$ respectively.

The intubation time was reported in fourteen publications with ATQ was shorter than with MAC $(\mathrm{MD}=-3.19 ; 95 \% \mathrm{Cl}:-9.33,2.95 ; \mathrm{p}=0.31$; $1^{2}=97 \%$; Figure 3) $[12,13,15-17,19,21-28]$. The endotracheal intubation during cervical spinal intubation was associated with significantly shorter procedure duration for ATQ than for MAC (MD = -10.30; $\left.95 \% \mathrm{Cl}:-18.43,-2.18 ; p=0.01 ; 1^{2}=74 \%\right)$. For intubation without cervical immobilization of the spine a slight superiority of ATQ over MAC in terms of intubation time was noted (MD $=-82 ; 95 \% \mathrm{Cl}:-7.85$, $\left.6.20 ; p=0.82 ;\left.\right|^{2}=98 \%\right)$. 


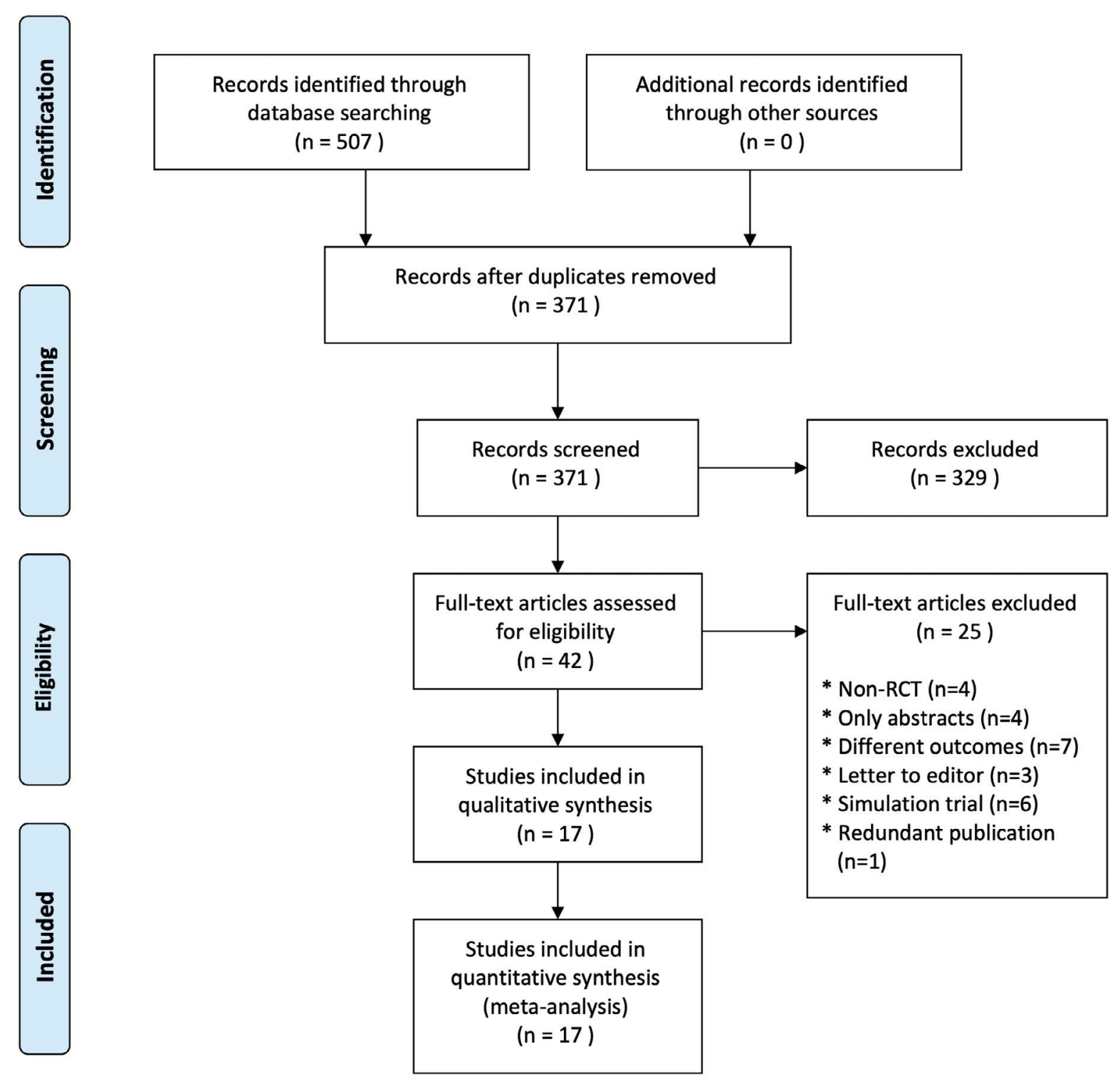

FIGURE 1. Flow diagram showing stages of database searching and study selection

\begin{tabular}{|c|c|c|c|c|c|c|c|c|c|}
\hline Study or Subgroup & \multicolumn{2}{|c|}{ ATQ } & \multicolumn{2}{|c|}{ MAC } & Weight & $\begin{array}{c}\text { Odds Ratio } \\
\mathrm{M}-\mathrm{H} \text {, Random, } 95 \% \mathrm{Cl}\end{array}$ & & \multicolumn{2}{|c|}{$\begin{array}{c}\text { Odds Ratio } \\
\text { M-H, Random, } 95 \% \mathrm{Cl}\end{array}$} \\
\hline Abdallah 2019 & 34 & 35 & 33 & 35 & $6.2 \%$ & $2.06[0.18,23.83]$ & & & \\
\hline Al-Ghamdi 2016 & 9 & 21 & 16 & 22 & $11.1 \%$ & $0.28[0.08,1.01]$ & & & \\
\hline Ertürk 2015 & 30 & 40 & 20 & 40 & $12.8 \%$ & $3.00[1.16,7.73]$ & & & \\
\hline Ferrando 2011 & 29 & 30 & 24 & 30 & $7.1 \%$ & $7.25[0.82,64.46]$ & & & \\
\hline Hosalli 2017 & 27 & 30 & 23 & 30 & $10.2 \%$ & $2.74[0.63,11.82]$ & & & \\
\hline Koh 2010 & 24 & 25 & 10 & 25 & $7.2 \%$ & $36.00[4.17,310.44]$ & & & \\
\hline Maharaj 2006 & 30 & 30 & 29 & 30 & $4.3 \%$ & $3.10[0.12,79.23]$ & & & \\
\hline Maharaj 2007 & 20 & 20 & 19 & 20 & $4.3 \%$ & $3.15[0.12,82.16]$ & & & \\
\hline Maharaj 2008 & 19 & 20 & 13 & 20 & $7.0 \%$ & $10.23[1.12,93.34]$ & & & \\
\hline McElwain 2011 & 28 & 28 & 25 & 31 & $5.0 \%$ & $14.53[0.78,270.92]$ & & & \\
\hline Nishiyama 2011 & 29 & 36 & 31 & 35 & $10.8 \%$ & $0.53[0.14,2.02]$ & & & \\
\hline Zhao 2014 & 54 & 74 & 26 & 75 & $14.0 \%$ & $5.09[2.53,10.24]$ & & & \\
\hline Total $(95 \% \mathrm{Cl})$ & & 389 & & 393 & $100.0 \%$ & $3.00[1.37,6.60]$ & & & \\
\hline Total events & 333 & & 269 & & & & & & \\
\hline $\begin{array}{l}\text { Heterogeneity: } \mathrm{Tau}^{2} \\
\text { Test for overall effec }\end{array}$ & $\begin{array}{l}1.03 ; \mathrm{Ch} \\
\mathrm{Z}=2.73\end{array}$ & $i^{2}=$ & $\begin{array}{l}0.04, \mathrm{df}= \\
0.006)\end{array}$ & $=$ & 02) & $I^{2}=63 \%$ & 0.01 & $\begin{array}{c} \\
0.1 \\
\text { Favours [ATQ] }\end{array}$ & $\begin{array}{lc}1 & 10 \\
\text { Favours } & \text { [MAC] }\end{array}$ \\
\hline
\end{tabular}

FIGURE 2. Forest plot of first intubation attempt success rate in Airtraq vs. Macintosh groups. The center of each square represents the odds ratio for individual trials, and the corresponding horizontal line stands for a $95 \%$ confidence interval. The diamonds represent pooled results 


\begin{tabular}{|c|c|c|c|c|c|c|c|c|c|c|c|c|}
\hline \multirow{2}{*}{ Study or Subgroup } & \multicolumn{3}{|c|}{ ATQ } & \multicolumn{3}{|c|}{ MAC } & \multicolumn{3}{|c|}{ Mean Difference } & \multirow{2}{*}{\multicolumn{2}{|c|}{$\begin{array}{c}\text { Mean Difference } \\
\text { IV, Random, } 95 \% \mathrm{CI}\end{array}$}} & \\
\hline & Mean & SD & Iotal & Mean & SD & Iotal & Weight & IV, Kandom, 95\% Cl & & & & \\
\hline Abdallah 2019 & 11.5 & 4.36 & 35 & 14.18 & 3.42 & 35 & $7.8 \%$ & $-2.68[-4.52,-0.84]$ & & - & & \\
\hline Al-Ghamdi 2016 & 56.4 & 6.02 & 21 & 35.1 & 8.61 & 22 & $7.5 \%$ & $21.30[16.88,25.72]$ & & & & \\
\hline Chalkeidis 2010 & 29.6 & 8.5 & 35 & 23.7 & 5.9 & 28 & $7.6 \%$ & $5.90[2.34,9.46]$ & & & - & \\
\hline Ertürk 2015 & 31.5 & 20.8 & 40 & 24.3 & 15.3 & 40 & $6.9 \%$ & $7.20[-0.80,15.20]$ & & & & \\
\hline Hindman 2014 & 19.6 & 7 & 14 & 21.6 & 7.8 & 14 & $7.3 \%$ & $-2.00[-7.49,3.49]$ & & & 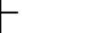 & \\
\hline Koh 2010 & 49.8 & 33.6 & 25 & 90 & 49.4 & 25 & $3.7 \%$ & $-40.20[-63.62,-16.78]$ & $\leftarrow$ & & & \\
\hline Maharaj 2006 & 12.2 & 8.5 & 30 & 12.4 & 9.2 & 30 & $7.5 \%$ & $-0.20[-4.68,4.28]$ & & & - & \\
\hline Maharaj 2007 & 13.2 & 5.4 & 20 & 20.3 & 12.2 & 20 & $7.3 \%$ & $-7.10[-12.95,-1.25]$ & & - & & \\
\hline Maharaj 2008 & 13.4 & 6.3 & 20 & 47.7 & 8.5 & 20 & $7.5 \%$ & $-34.30[-38.94,-29.66]$ & & $\longrightarrow$ & & \\
\hline McElwain 2011 & 19.8 & 3.8 & 29 & 26.8 & 9.5 & 31 & $7.6 \%$ & $-7.00[-10.62,-3.38]$ & & - & & \\
\hline Nishiyama 2011 & 39.8 & 14.2 & 36 & 36.5 & 18.5 & 35 & $7.0 \%$ & $3.30[-4.39,10.99]$ & & & & \\
\hline Vijayakumar 2016 & 25.8 & 3.8 & 45 & 22.4 & 2.8 & 45 & $7.8 \%$ & $3.40[2.02,4.78]$ & & & - & \\
\hline Zhao 2014 & 68 & 21 & 74 & 96 & 22 & 75 & $7.1 \%$ & $-28.00[-34.91,-21.09]$ & & 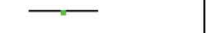 & & \\
\hline Çolak 2015 & 29.8 & 13.82 & 46 & 13.59 & 5.49 & 49 & $7.5 \%$ & $16.21[11.93,20.49]$ & & & $一$ & \\
\hline Total $(95 \% \mathrm{Cl})$ & & & 470 & & & 469 & $100.0 \%$ & $-3.19[-9.33,2.95]$ & & & & \\
\hline $\begin{array}{l}\text { Heterogeneity: } \mathrm{Tau}^{2}= \\
\text { Test for overall effect }\end{array}$ & $\begin{array}{l}125.7 \\
Z=1\end{array}$ & $\begin{array}{l}2 ; \mathrm{Chi}^{2} \\
02(\mathrm{P}=\end{array}$ & $=494.4$ & $46, \mathrm{df}$ & 13 & $<0.00$ & $001) ; 1^{2}=$ & $=97 \%$ & -5 & $\begin{array}{l}-25 \\
\text { Favours [ }\end{array}$ & Favour & $\begin{array}{l}25 \\
M A C]\end{array}$ \\
\hline
\end{tabular}

FIGURE 3. Forest plot of intubation time rate in Airtraq vs. Macintosh groups. The center of each square represents the mean difference for individual trials, and the corresponding horizontal line stands for a $95 \%$ confidence interval. The diamonds represent pooled results

\begin{tabular}{|c|c|c|c|c|c|c|c|c|c|}
\hline Study or Subgroup & \multicolumn{2}{|c|}{ ATQ } & $\begin{array}{c}\text { MAC } \\
\text { Events }\end{array}$ & Total & Weight & Odds Ratio & \multicolumn{3}{|c|}{$\begin{array}{c}\text { Odds Ratio } \\
\text { M-H, Fixed, } 95 \% \mathrm{Cl}\end{array}$} \\
\hline Abdallah 2019 & 35 & 35 & 35 & 35 & & Not estimable & & & \\
\hline Bhandari 2013 & 40 & 40 & 38 & 40 & $3.2 \%$ & $5.26[0.24,113.11]$ & & & \\
\hline Chalkeidis 2010 & 31 & 35 & 27 & 28 & $23.6 \%$ & $0.29[0.03,2.73]$ & & & \\
\hline Ertürk 2015 & 40 & 40 & 40 & 40 & & Not estimable & & & \\
\hline Ferrando 2011 & 29 & 30 & 30 & 30 & $10.2 \%$ & $0.32[0.01,8.24]$ & & & \\
\hline Hosalli 2017 & 30 & 30 & 30 & 30 & & Not estimable & & & \\
\hline Koh 2010 & 24 & 25 & 21 & 25 & $5.8 \%$ & $4.57[0.47,44.17]$ & & & \\
\hline Maharaj 2006 & 30 & 30 & 30 & 30 & & Not estimable & & & \\
\hline Maharaj 2007 & 20 & 20 & 19 & 20 & $3.2 \%$ & $3.15[0.12,82.16]$ & & & \\
\hline Maharaj 2008 & 20 & 20 & 16 & 20 & $2.7 \%$ & $11.18[0.56,222.98]$ & & & \\
\hline McElwain 2011 & 29 & 29 & 29 & 31 & $3.3 \%$ & $5.00[0.23,108.68]$ & & & \\
\hline Zhao 2014 & 65 & 74 & 50 & 75 & $41.6 \%$ & $3.61[1.55,8.42]$ & & & - \\
\hline Çolak 2015 & 4 & 50 & 1 & 50 & $6.3 \%$ & $4.26[0.46,39.54]$ & & & \\
\hline Total $(95 \% \mathrm{Cl})$ & & 458 & & 454 & $100.0 \%$ & $2.88[1.61,5.13]$ & & & \\
\hline Total events & 397 & & 366 & & & & & & \\
\hline $\begin{array}{l}\text { Heterogeneity: } \mathrm{Chi}^{2}= \\
\text { Test for overall effect }\end{array}$ & $\begin{array}{l}7.40, \mathrm{df} \\
\mathrm{Z}=3.58\end{array}$ & $\begin{array}{l}=8(P \\
3(P=\end{array}$ & $\begin{array}{l}=0.49) \\
.0003)\end{array}$ & $=0 \%$ & & & 0.01 & $\begin{array}{c}0.1 \\
\text { Favours [ATQ] }\end{array}$ & \begin{tabular}{|cc}
1 & 10 \\
Favours [MAC]
\end{tabular} \\
\hline
\end{tabular}

FIGURE 4. Forest plot of the overall intubation success rate in Airtraq vs. Macintosh groups. The center of each square represents the odds ratio for individual trials, and the corresponding horizontal line stands for a $95 \%$ confidence interval. The diamonds represent pooled results

\section{Secondary outcomes}

Thirteen studies indicated the total effectiveness of intubation, which for ATQ and MAC varied $86.7 \%$ vs. $80.6 \%$ respectively $(\mathrm{OR}=2.88 ; 95 \% \mathrm{Cl}: 1.61$, 5.13; $p<0.001 ;\left.\right|^{2}=0 \%$; Figure 4) [12, 14-18, 20-25, 28].

One study [16] indicated that cervical spine movements were lower for ATQ intubation than for MAC $(\mathrm{MD}=-12.70 ; 0.5 \% \mathrm{Cl}:-14.92,-10.48 ; \mathrm{p}<0.001)$.

Pooled analysis showed that ATQ intubation required less head positioning change during the procedure (23.0\%) than MAC (32.1\%; OR $=0.23 ; 95 \%$ $\left.\mathrm{Cl}: 0.01,5.16 ; p=0.35 ; I^{2}=87 \%\right)$. The need for external laryngeal manipulation was also lower (3.3\%) with ATQ than with MAC (36.6\%; OR $=0.07 ; 95 \%$ Cl: $\left.0.04,0.13 ; p<0.001 ; l^{2}=28 \%\right)$.

\section{Adverse events}

A detailed list of adverse events is presented in Table 2. The most common complication among the studies included in the meta-analysis was a sore throat and it concerned $41.7 \%$ of patients intubated with ATQ and $57.7 \%$ of those intubated with MAC. Intubation with ATQ was associated with a lower risk of blood staining of laryngoscope blade, laryngospasm, and mucosal trauma compared to MAC. In the case of lips trauma, an inverse relationship was noted, where trauma with ATQ was more than 5.5\% higher than with MAC.

\section{DISCUSSION}

In this review, we showed that Airtraq was the most useful device in terms of the success rate of the first 


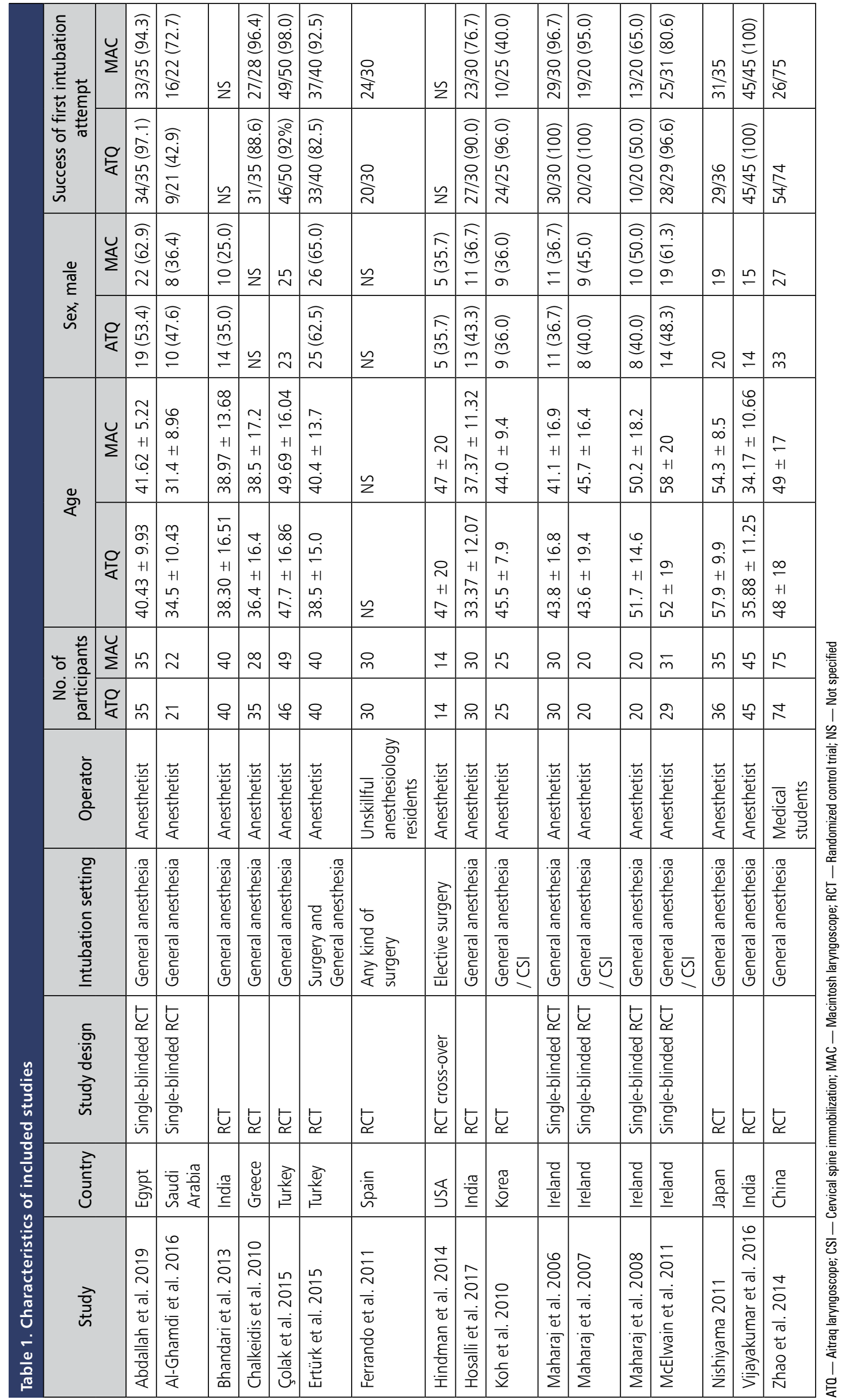




\begin{tabular}{|l|l|l|l|l|l|l|}
\hline \\
Table 2. Adverse events reported in included studies \\
\hline \multicolumn{1}{|c|}{ Type of adverse event } & $\begin{array}{c}\text { No. of } \\
\text { studies }\end{array}$ & $\begin{array}{c}\text { No. of incidence } \\
\text { in ATQ group }\end{array}$ & $\begin{array}{c}\text { No. of incidence } \\
\text { in Mac group }\end{array}$ & OR $(95 \%$ CI) & p value & I2 statistic \\
\hline Blood staining of laryngoscope blade & 2 & $1 / 64(1.6 \%)$ & $2 / 66(3.0 \%)$ & $0.49(0.04,5.61)$ & 0.56 & NA \\
\hline Sore throat & 3 & $40 / 96(41.7 \%)$ & $56 / 97(57.7 \%)$ & $0.23(0.04,1.20)$ & 0.08 & $56 \%$ \\
\hline Laryngosplasm & 1 & $0 / 35(0.0 \%)$ & $1 / 35(2.9 \%)$ & $0.32(0.01,8.23)$ & 0.49 & NA \\
\hline Hoarseness & 1 & $0 / 40(0.0 \%)$ & $0 / 40(0.0 \%)$ & NA & NA & NA \\
\hline Dental injury & 2 & $0 / 81(0.0 \%)$ & $0 / 82(0.0 \%)$ & NA & NA & NA \\
\hline Muscosal trauma & 1 & $1 / 21(4.8 \%)$ & $6 / 22(27.3 \%)$ & $0.13(0.01,1.22)$ & 0.07 & NA \\
\hline Lips trauma & 1 & $5 / 21(23.8 \%)$ & $4 / 22(18.2 \%)$ & $1.41(0.32,6.16)$ & 0.65 & NA \\
\hline
\end{tabular}

ATQ — Airtraq laryngoscope; MAC — Macintosh laryngoscope; OR — Odds Ratio; $\mathrm{Cl}$ — Confidence Interval; NA — Not applicable

attempt at endotracheal intubation under general anesthesia conditions. In the meta-analysis, the efficacy of the first intubation attempt with Airtraq was higher than with direct laryngoscopy. This relationship was even more evident when intubated under manual in-line neck stabilization. Many articles indicate the advantage of video laryngoscopy over direct laryngoscopy when intubating patients with 'difficult' airways (i.e. tongue edema) or when there are limitations in the patient's position due to the use of cervical collars $[29,30]$, manual in-line stabilization [31, 32] or continuous chest compression during cardiopulmonary resuscitation $[33,34]$. It is therefore advisable to use alternative intubation methods to Macintosh laryngoscope in such cases, which will increase the effectiveness of intubation as well as may shorten the time of the procedure. An additional problem observed with multiple endotracheal intubation attempts is the vicious circle phenomenon in which each subsequent intubation attempt increases soft tissue trauma - bleeding and swelling, leading ultimately to a situation described by the Difficult Airway Society (DAS) as 'can't intubate, can't ventilate' [35]. Then the only solution is cricothyrotomy or tracheostomy [36].

Rapid airway management including endotracheal intubation in both prehospital and operating theatre conditions is essential. The prolonged endotracheal intubation procedure may cause hypoxia and related damage to vital organs due to hypoxia. As Wozniak et al. indicate, intubation attempts should be limited to a maximum of 30 seconds. Prolonging the intubation more than 30 seconds leads to greater hypoxia and may contribute to increased neonatal morbidity, with no effect on success rate [37].

\section{Limitations}

There are some limitations in our analysis that deserve special attention. The first limitation is the fact that only randomized controlled trials are included in the study, but this type of study guarantees the highest quality of results. The second limitation is the inclusion of articles comparing only Airtraq vs. Macintosh laryngoscope. However, this was deliberate. In the further parts of the series of studies, the authors plan to conduct meta-analyses concerning other types of laryngoscopes.

\section{CONCLUSIONS}

This systematic review and meta-analysis revealed that ATQ can reduce the failed first intubation attempt, especially in cervical manual inline stabilization patients, and reduces the time needed to obtain airway management, but does not provide significant benefits on other adverse events associated with tracheal intubation. Further studies are needed to demonstrate whether severe adverse events are significantly different between the two devices.

Supplementary digital file Supplementary material related to this article can be found, in the online version, at: https://journals.viamedica. $\mathrm{pl} /$ disaster_and emergency medicine/article/ downloadS̄uppFile/DEMJ.a2021.0001/59938

Authors contributions: The authors' primary responsibilities were as follows: M.M. and L.S. developed the research question. M.M. and L.S., designed the study. M.M., J.S. and L.S. collected 
the data. M.M., J.S., and K.R. analyzed the data and interpreted the results. M.M. and L.S. wrote the manuscript. L.S. and J.S. handled tools and provided supervision.

\section{Funding sources: None.}

\section{Conflicts of interest: None.}

Acknowledgments: Study supported by the Polish Society of Disaster Medicine.

\section{REFERENCES}

1. Chen $X$, Jiao J, Cong $X$, et al. A comparison of the performance of the I-gel ${ }^{T M}$ vs. the LMA-S $S^{T M}$ during anesthesia: a meta-analysis of randomized controlled trials. PLoS One. 2013; 8(8): e71910, doi: 10.1371/ journal.pone.0071910, indexed in Pubmed: 23951266.

2. Saasouh W, Laffey K, Turan A, et al. Degree of obesity is not associated with more than one intubation attempt: a large centre experience. Br J Anaesth. 2018; 120(5): 1110-1116, doi: 10.1016/j.bja.2018.01.019, indexed in Pubmed: 29661388.

3. Higgs A, McGrath BA, Goddard C, et al. Difficult Airway Society, Intensive Care Society, Faculty of Intensive Care Medicine, Royal College of Anaesthetists. Guidelines for the management of tracheal intubation in critically ill adults. Br J Anaesth. 2018; 120(2): 323-352, doi: 10.1016/j.bja.2017.10.021, indexed in Pubmed: 29406182.

4. Szarpak L. Laryngoscopes for difficult airway scenarios: a comparison of the available devices. Expert Rev Med Devices. 2018; 15(9): 631-643, doi: 10.1080/17434440.2018.1511423, indexed in Pubmed: 30099914.

5. Meng L, Qiu H, Wan Li, et al. Intubation and Ventilation amid the COVID-19 Outbreak: Wuhan's Experience. Anesthesiology. 2020; 132(6): 1317-1332, doi: 10.1097/ALN.0000000000003296, indexed in Pubmed: 32195705.

6. Moher D, Shamseer L, Clarke M, et al. PRISMA-P Group. Preferred reporting items for systematic review and meta-analysis protocols (PRISMA-P) 2015 statement. Syst Rev. 2015; 4: 1, doi: 10.1186/20464053-4-1, indexed in Pubmed: 25554246.

7. Savović J, Weeks L, Sterne JAC, et al. Evaluation of the Cochrane Collaboration's tool for assessing the risk of bias in randomized trials: focus groups, online survey, proposed recommendations and their implementation. Syst Rev. 2014; 3: 37, doi: 10.1186/2046-4053-3-37, indexed in Pubmed: 24731537.

8. Ludwin K, Bialka S, Czyzewski L, et al. Video laryngoscopy for endotracheal intubation of adult patients with suspected/ confirmed COVID-19. A systematic review and meta-analysis of randomized controlled trials. Disaster and Emergency Medicine Journal. 2020, doi: 10.5603/demj.a2020.0023.

9. Hozo SP, Djulbegovic B, Hozo I. Estimating the mean and variance from the median, range, and the size of a sample. BMC Med Res
Methodol. 2005; 5: 13, doi: 10.1186/1471-2288-5-13, indexed in Pubmed: 15840177.

10. Higgins JPT, Thompson SG. Quantifying heterogeneity in a meta-analysis. Stat Med. 2002; 21(11): 1539-1558, doi: 10.1002/sim.1186, indexed in Pubmed: 12111919.

11. Higgins JP, Green S. Eds., Cochran Handbook for Systematic Review of Interventions: Assessing Risk of Bias in Included Studies (5.0.0 ed.), John Wiley \& Sons, Inc. 2008: Hoboken.

12. Abdallah SI, Gaballah KM. Endotracheal Intubation Criteria and Stress Response: Airtraq versus Macintosh Laryngoscopes - A Prospective Randomized Controlled Trial. Anesth Essays Res. 2019; 13(3): 430436, doi: 10.4103/aer.AER_80_19, indexed in Pubmed: 31602057.

13. Al-Ghamdi AA, EI Tahan MR, Khidr AM. Comparison of the Macintosh, GlideScope ${ }^{\circledR}$, Airtraq ${ }^{\circledR}$, and King Vision ${ }^{\text {TM }}$ laryngoscopes in routine airway management. Minerva Anestesiol. 2016; 82(12): 1278-1287, indexed in Pubmed: 27103030.

14. Bhandari G, Shahi KS, Asad M, et al. Airtraq(®) versus Macintosh laryngoscope: A comparative study in tracheal intubation. Anesth Essays Res. 2013; 7(2): 232-236, doi: 10.4103/0259-1162.118971, indexed in Pubmed: 25885839.

15. Chalkeidis 0 , Kotsovolis G, Kalakonas A, et al. A comparison between the Airtraq and Macintosh laryngoscopes for routine airway management by experienced anesthesiologists: a randomized clinical trial. Acta Anaesthesiol Taiwan. 2010; 48(1): 15-20, doi: 10.1016/ S1875-4597(10)60004-5, indexed in Pubmed: 20434108.

16. Çolak A, Çopuroğlu E, Yılmaz A, et al. A Comparison of the Effects of Different Types of Laryngoscope on the Cervical Motions: Randomized Clinical Trial. Balkan Med J. 2015; 32(2): 176-182, doi: 10.5152/ balkanmedj.2015.15335, indexed in Pubmed: 26167342.

17. Ertürk T, Deniz S, Şimşek F, et al. Comparison of the Macintosh and Airtraq Laryngoscopes in Endotracheal Intubation Success. Turk J Anaesthesiol Reanim. 2015; 43(3): 181-187, doi: 10.5152/ TJAR.2015.38278, indexed in Pubmed: 27366492.

18. Ferrando C, Aguilar G, Belda FJ. Comparison of the Laryngeal View during Tracheal Intubation Using Airtraq and Macintosh Laryngoscopes by Unskillful Anesthesiology Residents: A Clinical Study. Anesthesiol Res Pract. 2011; 2011: 301057, doi: 10.1155/2011/301057, indexed in Pubmed: 22162683.

19. Hindman BJ, Santoni BG, Puttlitz CM, et al. Intubation biomechanics: laryngoscope force and cervical spine motion during intubation with Macintosh and Airtraq laryngoscopes. Anesthesiology. 2014; 121(2): 260-271, doi: 10.1097/ALN.0000000000000263, indexed in Pubmed: 24739996.

20. Hosalli V, Arjun BK, Ambi U, et al. Comparison of Airtraq ${ }^{\text {TM }}$, McCoy ${ }^{\text {TM }}$ and Macintosh laryngoscopes for endotracheal intubation in patients with cervical spine immobilisation: A randomised clinical trial. Indian J Anaesth. 2017; 61(4): 332-337, doi: 10.4103/ija.IJA_517_16, indexed in Pubmed: 28515522.

21. Koh JC, Lee JS, Lee YW, et al. Comparison of the laryngeal view during intubation using Airtraq and Macintosh laryngoscopes in patients with 
cervical spine immobilization and mouth opening limitation. Korean J Anesthesiol. 2010; 59(5): 314-318, doi: 10.4097/kjae.2010.59.5.314, indexed in Pubmed: 21179292.

22. Maharaj $\mathrm{CH}$, Buckley E, Harte $\mathrm{BH}$, et al. Endotracheal intubation in patients with cervical spine immobilization: a comparison of macintosh and airtraq laryngoscopes. Anesthesiology. 2007; 107(1): 53-59, doi: 10.1097/01. anes.0000267529.71756.f0, indexed in Pubmed: 17585215.

23. Maharaj $\mathrm{CH}$, Costello JF, Harte BH, et al. Evaluation of the Airtraq and Macintosh laryngoscopes in patients at increased risk for difficult tracheal intubation. Anaesthesia. 2008; 63(2): 182-188, doi: 10.1111/j.1365-2044.2007.05316.x, indexed in Pubmed: 18211450.

24. Maharaj $\mathrm{CH}, \mathrm{O}^{\prime}$ Croinin $\mathrm{D}$, Curley $\mathrm{G}$, et al. A comparison of tracheal intubation using the Airtraq or the Macintosh laryngoscope in routine airway management: A randomised, controlled clinical trial. Anaesthesia. 2006; 61(11): 1093-1099, doi: 10.1111/j.1365-2044.2006.04819.x, indexed in Pubmed: 17042849.

25. McElwain J, Laffey JG. Comparison of the C-MAC ${ }^{\circledR}$, Airtraq ${ }^{\circledR}$, and Macintosh laryngoscopes in patients undergoing tracheal intubation with cervical spine immobilization. Br J Anaesth. 2011; 107(2): 258-264, doi: 10.1093/bja/aer099, indexed in Pubmed: 21586444.

26. Nishiyama T. Comparison of the Airtraq, Airway Scope, and disposable Macintosh laryngoscope blade. Middle East J Anaesthesiol. 2011; 21(1): 129-134, indexed in Pubmed: 21991747.

27. Vijayakumar V, Rao S, Shetty N. A Comparison of Macintosh and Airtraq Laryngoscopes for Endotracheal Intubation in Adult Patients With Cervical Spine Immobilization Using Manual In Line Axial Stabilization: A Prospective Randomized Study. J Neurosurg Anesthesiol. 2016; 28(4): 296-302, doi: 10.1097/ANA.0000000000000224, indexed in Pubmed: 26325513.

28. Zhao H, Feng Yi, Zhou Y. Teaching tracheal intubation: Airtraq is superior to Macintosh laryngoscope. BMC Med Educ. 2014; 14: 144, doi: 10.1186/1472-6920-14-144, indexed in Pubmed: 25027257.

29. Yuk M, Yeo W, Lee K, et al. Cervical collar makes difficult airway: a simulation study using the LEMON criteria. Clin Exp Emerg Med. 2018; 5(1): 22-28, doi: 10.15441/ceem.16.185, indexed in Pubmed: 29618189.

30. Smereka J, Ladny JR, Naylor A, et al. C-MAC compared with direct laryngoscopy for intubation in patients with cervical spine immobi- lization: A manikin trial. Am J Emerg Med. 2017; 35(8): 1142-1146, doi: 10.1016/j.ajem.2017.03.030, indexed in Pubmed: 28341185.

31. Gawlowski P, Smereka J, Madziala M, et al. Comparison of the ETView Single Lumen and Macintosh laryngoscopes for endotracheal intubation in an airway manikin with immobilized cervical spine by novice paramedics: A randomized crossover manikin trial. Medicine (Baltimore). 2017; 96(16): e5873, doi: 10.1097/MD.0000000000005873, indexed in Pubmed: 28422820.

32. Karczewska K, Szarpak L, Smereka J, et al. ET-View compared to direct laryngoscopy in patients with immobilized cervical spine by unexperienced physicians: A randomized crossover manikin trial. Anaesthesiol Intensive Ther. 2017; 49(4): 274-282, doi: 10.5603/AlT.a2017.0047, indexed in Pubmed: 28953308.

33. Evrin T, Smereka J, Gorczyca D, et al. Comparison of blind intubation via supraglottic airway devices versus standard intubation during different airway emergency scenarios in inexperienced hand: Randomized, crossover manikin trial. Medicine (Baltimore). 2018; 97(40): e12593, doi: 10.1097/MD.0000000000012593, indexed in Pubmed: 30290627.

34. Kurahashi N, Komasawa N, Watanabe N, et al. Successful tracheal intubation with the MCGRATH ${ }^{\text {TM }}$ MAC during chest compression in a difficult airway patient. J Clin Anesth. 2017; 39: 15-16, doi: 10.1016/j. jclinane.2017.03.017, indexed in Pubmed: 28494893.

35. Higgs A, McGrath BA, Goddard C, et al. Difficult Airway Society. DAS guidelines on the airway management of critically ill patients. Anaesthesia. 2018; 73(8): 1035-1036, doi: 10.1111/anae.14352, indexed in Pubmed: 30117585.

36. Ezri T, Szmuk P, Warters RD, et al. Difficult airway management practice patterns among anesthesiologists practicing in the United States: have we made any progress? J Clin Anesth. 2003; 15(6): 418-422, doi: 10.1016/s0952-8180(03)00080-1, indexed in Pubmed: 14652117.

37. Wozniak M, Arnell K, Brown M, et al. The 30-second rule: the effects of prolonged intubation attempts on oxygen saturation and heart rate in preterm infants in the delivery room. Minerva Pediatr. 2018; 70(2): 127-132, doi: 10.23736/50026-4946.16.04469-8, indexed in Pubmed: 27082272. 